\title{
Open reduction and percutaneous pinning for medial condyle fractures of elbow in children: is it a risk for complications?
}

\author{
Murat Demiroglu ${ }^{1}$, Bulent Kilic ${ }^{2}$, Koray Unay ${ }^{3}$, Korhan Ozkan ${ }^{1}$, Davut Aydın ${ }^{1}$ \\ ${ }^{1}$ Istanbul Medeniyet University, Goztepe EAH, Orthopaedics, Istanbul, Turkey \\ ${ }^{2}$ Gelisim University, Health Sciences, Istanbul, Turkey \\ ${ }^{3}$ Medivia Special Hospital, Istanbul, Turkey \\ Received: 26 May 2016 \\ Accepted: 31 May 2016 \\ *Correspondence: \\ Dr. Murat Demiroglu, \\ E-mail: drmuratdemiroglu@gmail.com
}

Copyright: ( ) the author(s), publisher and licensee Medip Academy. This is an open-access article distributed under the terms of the Creative Commons Attribution Non-Commercial License, which permits unrestricted non-commercial use, distribution, and reproduction in any medium, provided the original work is properly cited.

\section{ABSTRACT}

Background: There are limited cases of humerus medial condyle fracture in the literature treated by open reduction and percutaneous pinning. This study presents cases treated by open reduction and percutaneous pinning and discussed the problems reported in the literature.

Methods: Nine cases were treated by open reduction and percutaneous pinning between 2006-2014. These cases were followed for nonunion, avascular necrosis, range of motion, nerve lesion and infection for 15.3 months (range 11 to 18 months).

Results: No non-union, avascular necrosis, iatrogenic nerve lesion or infection developed in our cases. All patients gained full range of motion.

Conclusions: This study presents that surgical technique and early timing of surgery prevents the complications.

Keywords: Medial condyle, Fracture, Elbow, Children, Open reduction, Complication

\section{INTRODUCTION}

Medial condylar fractures of elbow in children are extremely rare and account for less than $1 \%$ of all elbow fractures. ${ }^{1-4}$ These are intra-articular, epiphyseal, and unstable injuries that carry definite risk of nonunion. Diagnosis can be challenging as trochlea ossifies much later than capitellum, usually around the age of nine. ${ }^{5}$ Missed fractures and delayed treatment usually lead to serious complications such as growth disturbance, articular incongruence and functional disability. ${ }^{6}$

Tenuous blood supply of trochlea is one of the major problems associated with the surgery of medial condyle of humerus. Blood supply of trochlea at this region is solely provided by terminal branches with no collateral supply. ${ }^{1,4,6}$ Blood flow may be easily disturbed if the soft tissue at the posterior of condyle is stripped off during the open surgery for exposure or reduction. ${ }^{5,7}$ This may lead to nonunion or avascular necrosis. Infection is also anticipated as in all open surgical techniques.

Generally open reduction of these fractures is avoided due to high risk of avascular necrosis. ${ }^{5,7}$ However, there is risk of ulnar nerve injury in closed percutaneous pinning. ${ }^{8}$ Rarely in some cases, ulnar nerve injury may be present before the operation and exploration of the nerve may be required. ${ }^{2,9}$ Thus, in our clinic we prefer open reduction and percutaneous pinning (ORPP) for instable fractures.

Case series in the literature usually involve small number of cases due to rarity of the fracture. Treatment methods include casting, closed reduction percutaneous pinning or ORPP. But relatively lower number of cases is treated by ORPP. Purpose of our study was to evaluate the incidence of nonunion, avascular necrosis, range of motion, nerve lesions and infection rates in our patients 
that were treated by ORPP through the posterolateral incision.

\section{METHODS}

All hospitalized cases of medial humeral condylar fractures between 1991 and 2006 were included into the study for follow-up. Age, sex, injured side, mechanism of injury, type of fracture, preoperative and postoperative complications such as ulnar nerve palsy or dislocations, radiological approaches, treatment, final range of motion and clinical and radiological follow-ups were recorded.

ORPP was performed for nine elbow medial condyle fractures of nine children between 1991 and 2006. Mechanism of the injury was falling on fully extended elbow in all patients. There were eight boys and one girl. Fractures involved left elbow in five and right elbow in four cases. Mean age of the patients was 7.6 years, range 1 to 16 years.

Classification system proposed by Bensahel defines type 1 fractures as minimally displaced fractures. Type 2 fractures are displaced with minimal rotation and type 3 fractures are both displaced and rotated. ${ }^{1}$

In present study, two patients were classified as type 2, and seven patients were classified as type 3 .

Diagnosis was apparent for six children because of displaced large metaphyseal bone fragment visualized in direct anteroposterior, lateral and oblique $\mathrm{X}$-rays. Remaining three patients required magnetic resonance imaging for definitive diagnosis.

One patient showed findings of ulnar nerve palsy at the initial physical examination. All children were referred to emergency unit at the day of injury.

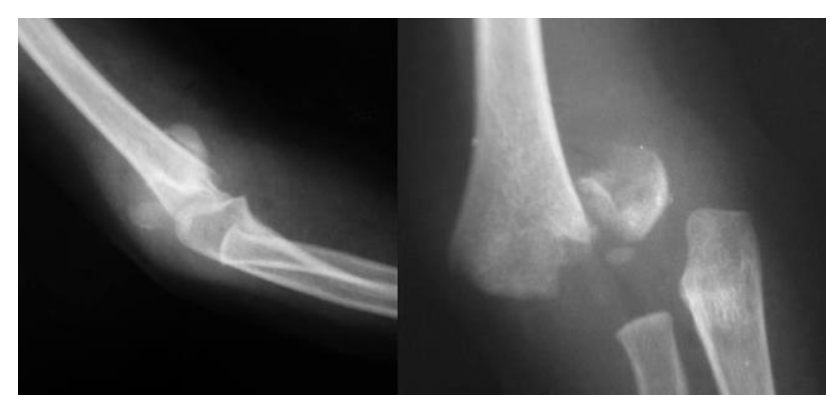

Figure 1: Anterior-posterior and lateral roentgenographic view of the 2 years old child's elbow, before the surgery.

All surgeries were performed within the first 12 hours after the injury. Posteromedial incision was used to provide exposure of both the fracture and ulnar nerve.

Dissection at the posterior surface of medial condylar fragment was avoided to prevent avascular necrosis.
Following open reduction of the fracture, internal fixation was achieved with two smooth $\mathrm{K}$-wires in eight patients (Figure 1,2 and 3) and with screw in one patient due to intraoperative problems of pinning with K-wires. Affected elbows were immobilized by long-arm cast postoperatively for a mean period of 4.3 weeks (range 4 to 5 weeks) until radiographic evidence of fracture healing was observed on direct $\mathrm{x}$-rays. Thereafter, cast was removed, and active and passive range of motion exercises was started.

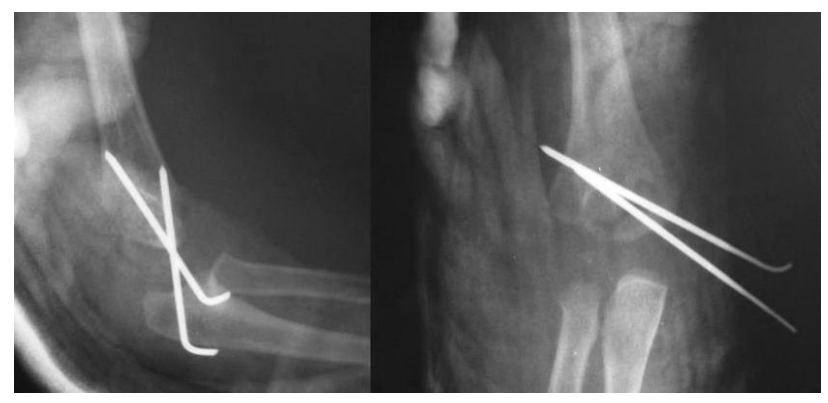

Figure 2: Anterior-posterior and lateral roentgenographic view of the 2 years old child's elbow, after the surgery.

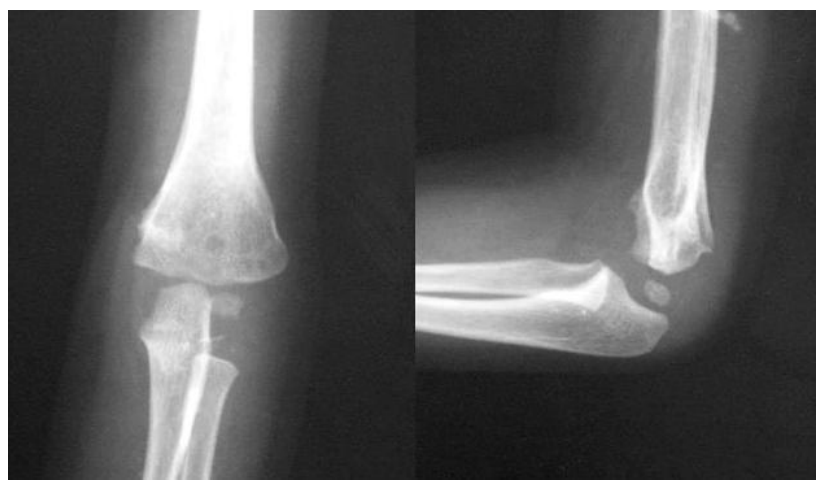

Figure 3: Anterior-posterior and lateral roentgenographic view of the 2 years old child's elbow, at the $16^{\text {th }}$ months after the surgery.

\section{RESULTS}

Age, sex, injury side, preoperative and postoperative complications such as ulnar palsy or dislocation, radiological approaches, medications, time of final radiological follow-up and incidence of avascular necrosis are shown in Table 1.

Average length of follow-up was 15.3 months (range 11 to 18 months). At final follow-up, all patients had full range of motion of the elbow with no loss in flexion, extension, pronation or supination. At the last follow-up $\mathrm{x}$-rays of the extremities were checked for deformity of elbow or avascular necrosis of the medial condyle. No avascular necrosis was detected.

Two patients $\left(2^{\text {nd }}\right.$ and $3^{\text {rd }}$ patients) developed $5^{\circ}$ and $10^{\circ}$ varus deformities respectively (Table 1$)$. No infection or 
nerve injury was observed during the postoperative follow-up. The child that had ulnar nerve palsy at the initial examination spontaneously recovered after the operation.

Table 1: Patients' information, diagnosis, follow-ups and complications.

\begin{tabular}{|lllllllll|}
\hline Patient & Age & Sex & Side & $\begin{array}{l}\text { First diagnostic } \\
\text { radiological } \\
\text { examinations }\end{array}$ & Dislocation & Immobilization & $\begin{array}{l}\text { Final } \\
\text { follow up } \\
\text { time } \\
\text { (month) }\end{array}$ & Complications \\
\hline 1 & 16 & Male & R & X-ray & No & 4 weeks & 14.5 & No \\
\hline 2 & 2 & Male & R & MRI & Yes & 5 weeks & 11 & $\begin{array}{l}5^{\circ} \text { varus } \\
\text { deformity }\end{array}$ \\
\hline 3 & 1 & Male & R & MRI & Yes & 4 weeks & 12 & $\begin{array}{l}10^{\circ} \text { varus } \\
\text { deformity }\end{array}$ \\
\hline 4 & 14 & Male & L & X-ray & Yes & 4 weeks & 16 & No \\
\hline 5 & 11 & Male & L & X-ray & No & 4 weeks & 17.5 & $\begin{array}{l}\text { Preop ulnar } \\
\text { nerve palsy }\end{array}$ \\
\hline 6 & 11 & Female & L & X-ray & No & 4 weeks & 18 & No \\
\hline 7 & 2 & Male & R & X-ray & Yes & 4 weeks & 16.5 & No \\
\hline 8 & 2 & Male & L & MRI & No & 4 weeks & 17 & No \\
\hline 9 & 10 & Male & L & X-ray & No & 5 weeks & 15 & No \\
\hline
\end{tabular}

\section{DISCUSSION}

There exists limited number of patients treated by ORPP in the literature. In the study cases treated by ORPP for potential complications of open surgery were followed. Study was aimed to discuss the differences between present case series and small number of cases reported in the literature.

First of all, present series is not large enough to draw definite conclusions. However it is one of the largest series of ORPP in the literature. There is no large scale study due to rarity of the medial condyle fracture. Studies usually have retrospective design. In the first years of present study, diagnosis of some cases may be delayed due to less frequent use of MRI. But these cases are not included and are beyond the scope of our study.

It was believed that urgent surgery was one of the major causes that have prevented avascular necrosis in our cases. All patients were operated within the first 12 hours. During exposure, dissection of the posterior surface of the medial condylar fragment was avoided to prevent avascular necrosis. ${ }^{10}$

Chacca reported the age of the children with medial humeral condyle fractures ranged between 8 to 12 years. Other series in the literature confirmed this age predilection. $^{2,4,5,11}$ However, this finding was not supported by present study. Six children in present study were out of the reported range. This discrepancy may be explained by ability of MRI to detect these fractures at a relatively early period. Mean period of casting for humerus medial condyle fractures has been reported as 3 to 4 weeks. ${ }^{1-5}$ Present casting period was 4 to 5 weeks. Four cases that also had dislocation were treated by open surgery, thus casting time to prevent loss of reduction was extended. Nevertheless, this relatively longer period of casting did not adversely affect the ROM of patients.

Iatrogenic ulnar nerve injury either before or after surgery of distal humerus is not rare. ${ }^{8}$ In present series, iatrogenic ulnar nerve injury was not observed because it was performed open surgery to provide sufficient exposure of the ulnar nerve. Only one case of ulnar nerve palsy due to fracture of medial condyle has been reported in the literature. ${ }^{12}$ it also includes one case which spontaneously recovered after open surgery.

Two major complications may be expected if the blood supply of the surrounding soft tissue envelope is disrupted during the open surgery; these are nonunion and infection. Fractures of the medial condyle have the risk of nonunion as they are intraarticular fractures like the fractures of lateral condyle. ${ }^{9,11}$ careful dissection of soft tissues during the open surgery prevented formation of non-union and osteomyelitis in present series.

Medial condyle fractures associated with dislocation of elbow have been reported. ${ }^{12}$ Major problem of these cases are reduced range of motion after the operation. Usually elbow flexion and extension are limited; pronation and supination are less commonly involved. Patients with elbow dislocation in our study did not experience a loss of range of motion. It was believed that this was achieved by urgent surgical treatment and anatomic reduction of fracture provided by open reduction. But two cases of 
dislocation developed varus deformity within acceptable limits.

These fractures can be detected at a relatively younger age by increased use of MRI. ${ }^{12,13}$ Artrography was frequently used before MRI, but its use has been considerably reduced, since it is an invasive method and MRI became widely available. Study was able to settle definitive diagnosis of three patients only after MRI. But it was believed that candidates of MRI must be selected after a comprehensive elbow examination due to the need for general anesthesia in younger children.

\section{CONCLUSION}

In the present study ORPP was performed for nine humerus medial condyle fractures. Mainly posterolateral incision to expose the ulnar nerve was preferred as well. The soft tissue posterior to the condyle was not stripped off. No nonunion, avascular necrosis, iatrogenic nerve lesion and infection were observed. All cases had full range of motion. It was believed that present surgical technique and early timing of surgery are effective for preventing complications.

Funding: No funding sources

Conflict of interest: None declared

Ethical approval: The study was approved by the institutional ethics committee

\section{REFERENCES}

1. Bensahel H, Csukonyi Z, Badelon O, Badaoui S. Fractures of the medial condyle of the humerus in children. J Pediatr Orthop. 1986;6:430-3.

2. Chacha PB. Fracture of the medical condyle of the humerus with rotational displacement. Report of two cases. J Bone Joint Surg Am. 1970;52:1453-8.

3. Ingersoll RE. Fractures of the humeral condyles in children. Clin Orthop Relat Res. 1965;41:32-42.
4. Papavasiliou V, Nenopoulos S, Venturis T. Fractures of the medial condyle of the humerus in childhood. $\mathrm{J}$ Pediatr Orthop. 1987;7:421-3.

5. Fowles JV, Kassab MT. Displaced fractures of the medial humeral condyle in children. J Bone Joint Surg Am. 1980;62:1159-63.

6. Hanspal RS. Injury to the humeral condyle in a child reviewed after 18 years. J Bone Joint Surg. 1985;67B:638-9.

7. Ippolito E, Tudisco C, Farsetti P, Caterini R. Fracture of the humeral condyles in children. Acta Orthop Scand. 1996;67:173-8.

8. Gosens T, Bongers KJ. Neurovascular complications and functional outcome in displaced supracondylar fractures of the humerus in children. Injury. 2003;34:267-73.

9. Kilfoyle RM. Fractures of the medial condyle and epicondyle of the elbow in children. Clin Orthop. 1965;41:43-50.

10. Haraldsson S. On osteochondrosis deformas juvenilis capituli humeri including investigation of intraosseous vasculature in distal humerus. Acta Orthop Scand Suppl. 1959;38:1-232.

11. Ghawabi MH. Fracture of the medial condyle of the humerus. J Bone Joint Surg Am. 1975;57:677-80.

12. Leet AI, Young C, Hoffer MM. Medial condyle fractures of the humerus in children. $\mathrm{J}$ Pediatr Orthop. 2002;22:2-7.

13. Griffith JF, Roebuck DJ, Cheng JC, Chan YL, Rainer $\mathrm{TH}, \mathrm{Ng} \mathrm{BK}$, et al. Acute elbow trauma in children: spectrum of injury revealed by MR imaging not apparent on radiographs. AJR Am J Roentgenol. 2001;176:53-60.

Cite this article as: Demiroglu M, Kilic B, Unay K, Ozkan K, Aydin D. Open reduction and percutaneous pinning for medial condyle fractures of elbow in children: is it a risk for complications? Int J Res Orthop 2016;2:36-9. 